\title{
Roadmap and strategy for overcoming infusion reactions to nanomedicines
}

\author{
Janos Szebeni ${ }^{1,2,3}$, Dmitri Simberg ${ }^{4}$, África González-Fernández ${ }^{5}$, Yechezkel Barenholz ${ }^{6}$ and \\ Marina A. Dobrovolskaia ${ }^{7 \star}$
}

\begin{abstract}
Infusion reactions (IRs) are complex, immune-mediated side effects that mainly occur within minutes to hours of receiving a therapeutic dose of intravenously administered pharmaceutical products. These products are diverse and include both traditional pharmaceuticals (for example biological agents and small molecules) and new ones (for example nanotechnology-based products). Although IRs are not unique to nanomedicines, they represent a hurdle for the translation of nanotechnology-based drug products. This Perspective offers a big picture of the pharmaceutical field and examines current understanding of mechanisms responsible for IRs to nanomedicines. We outline outstanding questions, review currently available experimental evidence to provide some answers and highlight the gaps. We review advantages and limitations of the in vitro tests and animal models used for studying IRs to nanomedicines. Finally, we propose a roadmap to improve current understanding, and we recommend a strategy for overcoming the problem.
\end{abstract}

mmune-mediated adverse effects may occur in patients after a pharmaceutical product is administered to treat or diagnose a disease $\mathrm{e}^{1-4}$. When such reactions occur minutes to hours after systemic, intravenous product administration, they are often called infusion reactions, hypersensitivity or anaphylaxis. However, there is no uniform terminology, and the use of these terms largely depends on the field of study (clinical oncology versus immunology, for example). The World Allergy Organization classifies hypersensitivity reactions (HSRs) as immediate (occurring within minutes to hours of exposure) or delayed (requiring days before clinical manifestation $)^{2,3}$. According to the World Allergy Organization Anaphylaxis Guideline, the term 'hypersensitivity' refers to reproducible symptoms occurring as the result of exposure to a defined stimulus; 'allergy' is defined as an HSR initiated by a specific immunological mechanism; and 'anaphylaxis' is classified as a severe, life-threatening, generalized or systemic HSR ${ }^{5}$. The European Society for Medical Oncology divides the reactions into anaphylactic and anaphylactoid, and proposes the term 'non-allergic anaphylaxis' instead of 'anaphylactoid' where there is a 'non-immunological cause' ${ }^{\text {' }}$. The European Network for Drug Allergy's definition is independent of the underlying immunological mechanism and categorizes the HSRs as immediate and non-immediate. Moreover, differences between European and American physicians exist in managing these reactions ${ }^{7}$. The National Cancer Institute Common Terminology Criteria for Adverse Events distinguishes between allergy, anaphylaxis and cytokine release syndrome (CRS) based on clinical manifestations ${ }^{8}$. The more commonly known Gell and Coombs classification is based on the underlying immunological mechanism and the time to manifestation, and includes four types: immediate/type I (developing within 15-30 minutes of exposure), type II (minutes to hours) and type III (3-8 hours); and delayed/type IV (48-72 hours) ${ }^{9}$.
Although many immune-mediated adverse effects exist, here we focus on IRs. These reactions are unintended and occur at therapeutic doses of various products ${ }^{4}$, including biological products (such as recombinant proteins and antibodies) ${ }^{10,11}$, therapeutic nucleic acids, low-molecular-weight drugs ${ }^{1,12}$, and complex nanotechnology-based formulations ${ }^{13-15}$ herein referred to as nanomedicines (Tables 1 and 2). Despite the difference in underlying mechanisms, IRs may have overlapping clinical manifestations. Patients with acute IRs experience various symptoms including, but not limited to, skin flushing or rash, chest and back pain, dyspnoea, wheezing, chills, fever and rigor (Tables 1 and 2). These adverse effects require timely and accurate assessment, and proper management to avoid severe and potentially fatal consequences. Severe IRs are rare and occur in less than $5 \%$ of patients ${ }^{4}$. The incidence may increase, however, when different drugs are used in combination (for example paclitaxel and carboplatin), when patients have a certain type of human leukocyte antigens (HLA; for example HLA-B ${ }^{\star 57: 01}$ and abacavir) or when there is an underlying viral infection (for example Epstein-Barr virus infection and penicillin $)^{6,13}$. Despite decades of research suggesting that the incidence of IRs depends on both pharmacodynamics and pharmacogenetics, it is largely unknown why some patients develop these reactions while others do not. The lack of uniform terminology and classification of the reactions further complicates the issue. As such, acute IRs cause substantial stress among patients and their families as well as care providers and regulatory agencies ${ }^{16}$. Several world-leading health authorities (the World Health Organization, the United States Food and Drug Administration ${ }^{17}$ and the European Medicines Agency) agree on the noxious nature of these adverse effects and the need for improved prevention and management ${ }^{6}$. These improvements largely depend on an understanding of mechanisms, but the molecular and

\footnotetext{
'Nanomedicine Research and Education Center, Institute of Pathophysiology, Semmelweis University, Budapest, Hungary. ${ }^{2}$ SeroScience Ltd, Budapest, Hungary. ${ }^{3}$ Department of Nanobiotechnology and Regenerative Medicine, Faculty of Health, Miskolc University, Miskolc, Hungary. ${ }^{4}$ Translational BioNanosciences Laboratory, University of Colorado Skaggs School of Pharmacy and Pharmaceutical Sciences, Aurora, CO, USA. ${ }^{5}$ Immunology, Centro de Investigaciones Biomédicas (CINBIO), Centro de Investigación Singular de Galicia, Instituto de Investigación Sanitaria Galicia Sur (IIS-GS), University of Vigo, Vigo, Spain. ${ }^{6}$ Department of Biochemistry, Institute for Medical Research Israel-Canada, Hebrew University-Hadassah Medical School, Jerusalem, Israel. ${ }^{7}$ Nanotechnology Characterization Laboratory, Cancer Research Technology Program, Frederick National Laboratory for Cancer Research sponsored by the National Cancer Institute, Frederick, MD, USA. *e-mail: marina@mail.nih.gov
} 


\section{Table 1 | Selected examples of nanotechnology-based drug products known to induce IR}

\begin{tabular}{|c|c|c|c|c|c|c|c|}
\hline $\begin{array}{l}\text { Brand name } \\
\text { (manufacturer) }\end{array}$ & \multicolumn{2}{|c|}{ Active ingredient } & \multicolumn{2}{|c|}{ Indication } & \multicolumn{2}{|c|}{ Type of particle (size) } & Symptoms \\
\hline $\begin{array}{l}\text { Doxil, Caelyx (Johnson } \\
\text { \& Johnson) }\end{array}$ & \multicolumn{2}{|c|}{ Doxorubicin } & \multicolumn{2}{|c|}{$\begin{array}{l}\text { Ovarian cancer, Kaposi sarcoma, } \\
\text { myeloma }\end{array}$} & \multicolumn{2}{|c|}{ Liposomes (80-100 nm) } & $\begin{array}{l}\text { Flushing, shortness of breath, facial } \\
\text { swelling, headache, chills, back pain, } \\
\text { tightness in the chest or throat, } \\
\text { hypotension }\end{array}$ \\
\hline Myocet (Elan) & \multicolumn{2}{|c|}{ Doxorubicin } & \multicolumn{2}{|c|}{ Multiplex } & \multicolumn{2}{|l|}{ Liposomes } & $\begin{array}{l}\text { Flushing, dyspnoea, fever, facial swelling, } \\
\text { headache, back pain, chills, tightness in } \\
\text { the chest and throat, hypotension }\end{array}$ \\
\hline Abelcet (Elan, Enzon) & \multicolumn{2}{|c|}{ Amphotericin B } & \multicolumn{2}{|c|}{ Fungal infections } & \multicolumn{2}{|c|}{$\begin{array}{l}\text { Solid microparticles } \\
(1.6-11 \mathrm{~mm})\end{array}$} & $\begin{array}{l}\text { Shortness of breath, change in blood } \\
\text { pressure }\end{array}$ \\
\hline $\begin{array}{l}\text { Ambisome (Gilead, } \\
\text { Fujisawa) }\end{array}$ & \multicolumn{2}{|c|}{ Amphotericin B } & \multicolumn{2}{|c|}{ Fungal infections } & \multicolumn{2}{|c|}{ Liposomes (45-80 nm) } & $\begin{array}{l}\text { Chills, rigors, fever, nausea, vomiting, } \\
\text { cardiorespiratory events }\end{array}$ \\
\hline $\begin{array}{l}\text { Amphotec, Amphocyl } \\
\text { (Elan) }\end{array}$ & \multicolumn{2}{|c|}{ Amphotericin B } & \multicolumn{2}{|c|}{ Fungal infections } & \multicolumn{2}{|c|}{$\begin{array}{l}\text { Disk-shaped solid } \\
\text { nanoparticles (115 nm) }\end{array}$} & $\begin{array}{l}\text { Hypotension, tachycardia, bronchospasm, } \\
\text { dyspnoea, hypoxia, hyperventilation }\end{array}$ \\
\hline DaunoXome (Gilead) & \multicolumn{2}{|c|}{ Daunorubicin } & \multicolumn{2}{|c|}{ Kaposi sarcoma } & \multicolumn{2}{|c|}{ Liposomes (45 nm) } & Back pain, flushing, chest tightness \\
\hline Visudyne (Novartis) & \multicolumn{2}{|c|}{ Verteporfin } & \multicolumn{2}{|c|}{$\begin{array}{l}\text { Age-related macular } \\
\text { degeneration }\end{array}$} & \multicolumn{2}{|c|}{$\begin{array}{l}\text { Multilamellar liposomes } \\
\text { (multimicrometre) }\end{array}$} & $\begin{array}{l}\text { Chest pain, syncope, sweating, dizziness, } \\
\text { rash, dyspnoea, flushing, changes in blood } \\
\text { pressure and heart rate, back pain }\end{array}$ \\
\hline $\begin{array}{l}\text { Onivyde (Merrimack } \\
\text { Pharmaceuticals) }\end{array}$ & \multicolumn{2}{|c|}{ Irinotecan } & \multicolumn{2}{|c|}{$\begin{array}{l}\text { Metastatic pancreatic } \\
\text { adenocarcinoma progressing } \\
\text { after gemcitabine-based therapy }\end{array}$} & \multicolumn{2}{|l|}{ Liposomes } & $\begin{array}{l}\text { Rash, urticaria, periorbital oedema } \\
\text { (pruritus) }\end{array}$ \\
\hline $\begin{array}{l}\text { Vyxeos (Jazz } \\
\text { Pharmaceuticals) }\end{array}$ & \multicolumn{2}{|c|}{$\begin{array}{l}\text { Daunorubicin and } \\
\text { cytarabine }\end{array}$} & \multicolumn{2}{|c|}{$\begin{array}{l}\text { Newly diagnosed therapy-related } \\
\text { acute myeloid leukaemia (AML) } \\
\text { and } \mathrm{AML} \text { with myelodysplasia- } \\
\text { related changes }\end{array}$} & d Liposomes & & $\begin{array}{l}\text { Dyspnoea, headaches, chills, rash, nausea, } \\
\text { vomiting, oedema }\end{array}$ \\
\hline \multicolumn{2}{|c|}{ Brand name (manufacturer) } & \multicolumn{2}{|c|}{ Active ingredient } & Indication & $\begin{array}{l}\text { Micelle-forming } \\
\text { excipient (size) }\end{array}$ & \multicolumn{2}{|c|}{ Symptoms } \\
\hline \multicolumn{2}{|l|}{$\begin{array}{l}\text { Fasturec, Elitec (Sanofi } \\
\text { Aventis) }\end{array}$} & \multicolumn{2}{|l|}{ Rasburicase } & Hyperuricaemia & $\begin{array}{l}\text { Poloxamer-188 } \\
(\sim 15 \mathrm{~nm})\end{array}$ & \multicolumn{2}{|c|}{$\begin{array}{l}\text { Anaphylaxis, bronchospasm, chest pain, diarrhoea, } \\
\text { dyspnoea, fever, headache, hypotension, nausea, } \\
\text { rash, rhinitis, urticaria, vomiting }\end{array}$} \\
\hline \multicolumn{2}{|c|}{ Taxol (Bristol-Myers Squibb) } & Paclitaxel & & Cancer & $\begin{array}{l}\text { Cremophor EL } \\
(8-20 \mathrm{~nm})\end{array}$ & $\begin{array}{l}\text { Acute } \\
\text { angio } \\
\text { dyspn } \\
\text { rash, }\end{array}$ & $\begin{array}{l}\text { respiratory distress, anaphylaxis, } \\
\text { dema, arrhythmias, bronchospasm, chills, } \\
\text { ea, facial and upper thorax flushing, fever, } \\
\text { udden death, tachycardia, urticaria, wheezing }\end{array}$ \\
\hline $\begin{array}{l}\text { Cyclosporine injection, } \\
\text { (Draxis Pharma) }\end{array}$ & & Cyclosporin & & Immunosuppression & $\begin{array}{l}\text { Cremophor EL } \\
(8-20 \mathrm{~nm})\end{array}$ & $\begin{array}{l}\text { Acute } \\
\text { angio } \\
\text { dyspn } \\
\text { rash, }\end{array}$ & $\begin{array}{l}\text { respiratory distress, anaphylaxis, } \\
\text { dema, arrhythmias, bronchospasm, chills, } \\
\text { ea, facial and upper thorax flushing, fever, } \\
\text { ldden death, tachycardia, urticaria, wheezing }\end{array}$ \\
\hline $\begin{array}{l}\text { Vumon injection (Bristo } \\
\text { Myers Squibb) }\end{array}$ & & Teniposide & & Leukaemia & $\begin{array}{l}\text { Cremophor EL } \\
(8-20 \mathrm{~nm})\end{array}$ & $\begin{array}{l}\text { Acute } \\
\text { angio } \\
\text { dyspn } \\
\text { rash, }\end{array}$ & $\begin{array}{l}\text { respiratory distress, anaphylaxis, } \\
\text { dema, arrhythmias, bronchospasm, chills, } \\
\text { ea, facial and upper thorax flushing, fever, } \\
\text { udden death, tachycardia, urticaria, wheezing }\end{array}$ \\
\hline $\begin{array}{l}\text { Etoposide (Gensia Sicor } \\
\text { Pharmaceuticals) }\end{array}$ & & Podophyllot & xin & Different cancers & $\begin{array}{l}\text { Polysorbate } 80 \\
(8-16 \mathrm{~nm})\end{array}$ & $\begin{array}{l}\text { Apno } \\
\text { cyano } \\
\text { facial } \\
\text { loss o } \\
\text { in thro }\end{array}$ & $\begin{array}{l}\text { a, back pain, bronchospasm, chills, coughing, } \\
\text { is, diaphoresis, dyspnoea, fever, flushing, } \\
\text { welling, hyper or hypotension, laryngospasm, } \\
\text { consciousness, rash, tachycardia, tightness } \\
\text { at, tongue swelling, urticaria }\end{array}$ \\
\hline Taxotere (Sanofi-Aventi & & Docetaxel & & & $\begin{array}{l}\text { Polysorbate } 80 \\
(8-16 \mathrm{~nm})\end{array}$ & $\begin{array}{l}\text { Back } \\
\text { dyspn } \\
\text { flushi }\end{array}$ & $\begin{array}{l}\text { ain, bronchospasm, chest tightness, chills, } \\
\text { ea, erythema, fatal anaphylaxis, fever, } \\
\text { g, generalized rash, hypotension }\end{array}$ \\
\hline
\end{tabular}

Table based on numerous studies reviewed in refs ${ }^{18,57-59}$.

cellular processes causing IRs are incompletely understood. Therefore, IRs in patients are currently managed by systemic administration of immunosuppressive, anti-pyretic and anti-inflammatory medications before the infusion, during administration or both ${ }^{1,4,6}$.

Although not unique to any specific drug category, IRs present yet another hurdle in the translation of nanomedicines, owing to the complexity of both their nature and the regulatory approval process. This problem warrants thorough investigation; here, we examine the issue in the context of nanomedicines. We analyse the current understanding of the mechanisms underlying IRs as well as assays and models being used to study these reactions at the preclinical stage. We identify gaps in the knowledge and propose a roadmap to 


\begin{tabular}{|c|c|c|c|c|}
\hline Brand name (manufacturer) & $\begin{array}{l}\text { mAb, type (target } \\
\text { antigen) }\end{array}$ & Indication & Incidence & Symptoms \\
\hline Avastin (Genentech/Roche) & $\begin{array}{l}\text { Bevacizumab, } \\
\text { recombinant humanized } \\
\operatorname{lgG}_{1}(\text { VEGF-A) }\end{array}$ & $\begin{array}{l}\text { Combination } \\
\text { chemotherapy of } \\
\text { metastatic colon, lung, } \\
\text { kidney cancer and } \\
\text { glioblastoma }\end{array}$ & $\begin{array}{l}<3 \% \text {; severe } \\
0.2 \%\end{array}$ & $\begin{array}{l}\text { Chest pain, diaphoresis, headache, } \\
\text { hypertension, neurologic signs and symptoms, } \\
\text { oxygen desaturation, rigors, wheezing }\end{array}$ \\
\hline Campath (Genzyme) & $\begin{array}{l}\text { Alemtuzumab)-IH, } \\
\text { recombinant, humanized } \\
\text { IgG, } \mathrm{k}(\mathrm{CD} 52 \text { on } \mathrm{T} \text { and } \mathrm{B} \\
\text { cells) }\end{array}$ & $\begin{array}{l}\text { B-cell chronic } \\
\text { lymphocytic leukaemia } \\
(B-C L L)\end{array}$ & $4-7 \%$ & $\begin{array}{l}\text { Bronchospasm, chills, dyspnoea, emesis, fever, } \\
\text { hypotension, nausea, pyrexia, rash, rigors, } \\
\text { tachycardia, urticaria }\end{array}$ \\
\hline $\begin{array}{l}\text { Erbitux (Bristol-Myers Squibb, } \\
\text { Eli Lilly) }\end{array}$ & $\begin{array}{l}\text { Cetuximab, chimeric } \\
\text { IgG, } \mathrm{k} \text { (human EGFR) }\end{array}$ & $\begin{array}{l}\text { Metastatic colorectal } \\
\text { cancer, head and neck } \\
\text { cancer, squamous cell } \\
\text { carcinomas }\end{array}$ & $\begin{array}{l}<3 \% \text {; fatal }< \\
0.1 \%\end{array}$ & $\begin{array}{l}\text { Anaphylaxis, angioedoema, bronchospasm, } \\
\text { cardiac arrest, chills, dizziness, dyspnoea, fever, } \\
\text { hoarseness, hypotension, pruritus, rash, rigor, } \\
\text { stridor, urticaria, wheezing }\end{array}$ \\
\hline Herceptin (Genentech) & $\begin{array}{l}\text { Trastuzumab, humanized } \\
\text { IgG } \mathrm{k} \text { (human EGFR } \\
\text { receptor } 2, \mathrm{HER} 2 / \mathrm{neu} / \\
\text { erbB2) }\end{array}$ & $\begin{array}{l}\text { Metastatic breast and } \\
\text { gastric cancer }\end{array}$ & $<1 \%$ & $\begin{array}{l}\text { Asthenia, bronchospasm, chills, death within } \\
\text { hours, dizziness, dyspnoea, further pulmonary } \\
\text { complications, headache, hypotension, hypoxia, } \\
\text { nausea, pain, rash, severe hypotension, vomiting }\end{array}$ \\
\hline $\begin{array}{l}\text { Mylotarg (Pfizer/Wyeth } \\
\text { Pharmaceuticals) }\end{array}$ & $\begin{array}{l}\text { Gemtuzumab ozogamicin, } \\
\text { recombinant humanized } \\
\operatorname{lgG}_{4} \mathrm{k} \text { (CD33 on } \\
\text { haematopoietic cells) }\end{array}$ & $\begin{array}{l}\text { CD33 positive acute } \\
\text { myeloid leukaemia in } \\
\text { first relapse }\end{array}$ & $<8 \%$ & $\begin{array}{l}\text { Acute respiratory distress syndrome, } \\
\text { anaphylaxis, dyspnoea, fatal anaphylaxis, } \\
\text { hypotension, pulmonary oedema }\end{array}$ \\
\hline Vectibix (Amgen) & $\begin{array}{l}\text { Panitumumab, } \\
\text { recombinant humanized } \\
\operatorname{lgG}_{2} \mathrm{k} \text { (human EGFR) }\end{array}$ & $\begin{array}{l}\text { KRAS+ metastatic } \\
\text { colorectal carcinoma }\end{array}$ & $1-4 \%$ & $\begin{array}{l}\text { Anaphylactic reaction, bronchospasm, chills, } \\
\text { fever, hypotension }\end{array}$ \\
\hline Rituxan (Genentech) & $\begin{array}{l}\text { Rituximab, chimeric lgG } \mathrm{k} \\
(\mathrm{CD} 20 \text { on } \mathrm{B} \text { cells) }\end{array}$ & $\begin{array}{l}\text { B-cell leukaemia, } \\
\text { rheumatoid arthritis, and } \\
\text { non-Hodgkin's B-cell } \\
\text { lymphoma }\end{array}$ & $\begin{array}{l}>80 \% \\
\text { severe }<10 \%\end{array}$ & $\begin{array}{l}\text { Acute respiratory distress syndrome (ARDS), } \\
\text { bronchospasm, cardiogenic shock, flushing, } \\
\text { hypotension, hypoxia, itching, myocardial } \\
\text { infarction, pain (at the site of the tumour), } \\
\text { pulmonary infiltrates, runny nose, swelling of the } \\
\text { tongue or throat, ventricular fibrillation, vomiting }\end{array}$ \\
\hline
\end{tabular}

Table based on numerous studies reviewed in refs ${ }^{11,}$

fill them. We further suggest a strategy for overcoming translational barriers of nanomedicines caused by IRs.

\section{Mechanisms of IRs in humans}

According to Gell and Coombs, type I HSRs are mediated by immunoglobulin E ( $\operatorname{gE} \mathrm{E})$ specific to at least one component of a drug product (Table 3$)^{9}$. The main cellular contributors to this HSR type are mast cells, the activation of which leads to hay fever, allergic asthma and/or anaphylactic shock ${ }^{9,13}$. Type II HSR is cytotoxic hypersensitivity mediated by drug-specific antibodies (mainly IgG), the complement system and natural killer cells. Symptoms include pemphigus, nephritis, autoimmune haemolytic anaemia and Goodpasture's syndrome $^{9,13}$. Type III HSRs are mediated by the immune complexes formed between a drug and an antibody (either IgM or IgG), and they involve complement activation. Clinical manifestations are serum sickness, fever, glomerulonephritis and vasculitis ${ }^{9,13}$. Type IV HSRs are mediated by T-helper cells and macrophages and manifest as erythema, induration, contact dermatitis, maculopapular rash and granuloma ${ }^{9,13}$. An immediate IgE-independent HSR with symptoms resembling a type I HSR is known as a complement activationrelated pseudo-allergy (CARPA $)^{18}$.

Type I-III reactions and CARPA are commonly recognized mechanisms associated with drug-mediated HSRs. Platinumbased formulations are notorious for type I HSRs ${ }^{4,6}$, while CARPA is the best-studied reaction to nanomaterials ${ }^{18,19}$. CARPA has been described for liposomal drugs (Doxil and Ambisome), micelles (Taxol and Taxotere) and modified dextran-coated iron oxides (Feraheme), all of which are approved for clinical use and are marketed with a black box warning of potentially life-threatening IRs. Properties of nanomaterials commonly associated with CARPA are summarized in Fig. 1a. Uncontrolled release of cytokines resulting from excessive proinflammatory stimuli, inadequate regulation of inflammation or a combination thereof is responsible for severe CRS. The clinical manifestations of CRS include erythematous or pruritic rash, hypotension, fever, malaise, tachycardia, tachypnoea, generalized swelling, altered mental status, diffuse lymphadenopathy, and enlargement of the liver and spleen ${ }^{20}$. CRS created translation barriers for immunotherapies (for example CAR-T cells), biologics (for example TGN1412) and nanotechnology-formulated

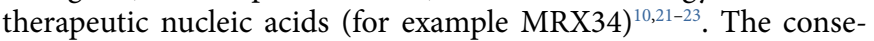
quences were severe and, in some cases, fatal ${ }^{23}$. It is important to mention that in some cases (CAR-T therapy, for example), clinical CRS manifestations are not immediate and may take a week or more, which further complicates IR definition, diagnosis and intervention. Moreover, some infections (such as influenza virus and bacteraemia) may trigger cytokine release with symptoms indistinguishable from the drug-mediated $\mathrm{CRS}^{24}$. Although various nanoformulations can induce the release of cytokines both in vitro and in vivo $^{25}$, the relevance of this mechanism to various types of nanomedicine-triggered IRs remains largely unknown.

The IRs to drugs are often heterogeneous and involve overlapping reactions and effector cells. For example, activation of the complement system, which occurs in CARPA, is also involved in the pathogenesis of type II and type III HSRs. Conversely, the macrophages may contribute both to type IV HSRs and to CARPA. Cytokines that are produced by leukocytes are involved in CRS 


\begin{tabular}{|c|c|c|c|c|}
\hline & Type I & Type II & Type III & Type IV \\
\hline Underlying mechanism & $\begin{array}{l}\text { Immediate } \\
\text { hypersensitivity or } \\
\text { acute allergy }\end{array}$ & $\begin{array}{l}\text { Antibody-mediated } \\
\text { cytotoxic reaction }\end{array}$ & Immune-complex-mediated reaction & Delayed-type hypersensitivity \\
\hline Mediators & $\lg E$ & $\begin{array}{l}\text { Cytotoxic } \lg M \text { and } \lg G \\
\text { antibodies }\end{array}$ & Immune complexes (mostly lgM) & $\begin{array}{l}\text { Mainly T-helper cells and } \\
\text { macrophages. No antibodies } \\
\text { involved }\end{array}$ \\
\hline Immune response & $\begin{array}{l}\text { Degranulation } \\
\text { (histamine release) } \\
\text { of mast cells } \\
\text { and basophils } \\
\text { and synthesis of } \\
\text { new mediators } \\
\text { (thromboxanes, } \\
\text { prostaglandins and } \\
\text { leukotrienes) }\end{array}$ & $\begin{array}{l}\text { Cytotoxic actions by } \\
\text { natural killer (NK) } \\
\text { cells, macrophages, } \\
\text { neutrophils and } \\
\text { complement }\end{array}$ & $\begin{array}{l}\text { Deposit of immune complexes in } \\
\text { tissues. Inflammatory response involving } \\
\text { complement activation, neutrophil } \\
\text { degranulation and platelet activation }\end{array}$ & $\begin{array}{l}\text { Cytotoxicity and accumulation } \\
\text { of macrophages and T cells. } \\
\text { Cytokine release and lymphocyte } \\
\text { stimulation }\end{array}$ \\
\hline Time to develop & $\begin{array}{l}\text { Usually from } \\
\text { minutes (15-30 } \\
\text { minutes) to a } \\
\text { few hours. Late- } \\
\text { onset reactions } \\
\text { (18-24 hours) are } \\
\text { uncommon }\end{array}$ & $\begin{array}{l}\text { From minutes to } \\
\text { hours, but some } \\
\text { clinical manifestations } \\
\text { (thrombocytopenia, } \\
\text { agranulocytosis, fever, } \\
\text { anaemia) can be } \\
\text { diagnosed after a few } \\
\text { days }\end{array}$ & $\begin{array}{l}\text { From 3-8 hours, but some clinical } \\
\text { manifestations can develop even 9-11 } \\
\text { days after exposure }\end{array}$ & Several (2-14) days \\
\hline Clinical symptoms & $\begin{array}{l}\text { Urticaria, } \\
\text { angioedema, } \\
\text { asthma, rhinitis, } \\
\text { conjunctivitis, } \\
\text { cardio-respiratory } \\
\text { anaphylactic shock, } \\
\text { bronchospasm }\end{array}$ & $\begin{array}{l}\text { Pemphigus, nephritis, } \\
\text { autoimmune haemolytic } \\
\text { anaemia, Goodpasture } \\
\text { syndrome }\end{array}$ & $\begin{array}{l}\text { Tissue injury. Several organs can be } \\
\text { affected: lungs, joints, skin and kidneys. } \\
\text { In addition, serum sickness, fever, } \\
\text { glomerulonephritis, and vasculitis are } \\
\text { possible }\end{array}$ & $\begin{array}{l}\text { Most common: skin eruptions } \\
\text { exposed to chemicals, cosmetics, } \\
\text { drugs, and metals. Contact } \\
\text { dermatitis, erythema, induration, } \\
\text { maculopapular rash, and } \\
\text { granuloma }\end{array}$ \\
\hline
\end{tabular}

Allergic reactions are separated into four types based on the underlying mechanism, time of symptom occurrence, mediators and clinical manifestation. This summary is based on ref. ${ }^{~}$.

and can contribute to various types of HSRs, including pseudoallergy. An excellent demonstration of the complexity of frequently overlapping mechanisms that cause IRs to nanomedicines comes from the experiences with liposomes and lipid-based nanocarriers, which, according to a recent report by the US Food and Drug Administration, dominate the current landscape of nanomedicine ${ }^{26}$. Research groups worldwide have reported that lipid-based carriers are not immunologically inert ${ }^{25,27,28}$. Preferential clearance of these materials by macrophages, activation of proinflammatory cytokines and the complement system are well-established ${ }^{25,27,28}$. However, the cause-effect relationship between the complement activation, cell uptake and cytokine release is far from being understood. Despite the general acceptance that IRs involve multiple cellular and biochemical processes, the controversy over the leading cause of this toxicity creates considerable hurdles and delays in the development of a unified strategy for predicting and overcoming the IRs to nanomedicines.

\section{Controversy surrounding mechanisms}

Activation of pulmonary intravascular macrophages (PIMs) by PEGylated liposomes (where PEG is polyethylene glycol) was suggested as a key effector arm of CARPA in pigs ${ }^{29}$. The proposed double-hit scenario in this mechanism implies that both the complement and macrophage activation trigger the IRs symptoms ${ }^{29}$. Recently, a study of polystyrene beads in the same model concluded that PIMs activation is the leading cause of HSRs to nanomaterials and challenged the role of the complement ${ }^{30}$. This mechanism caused robust debate ${ }^{31,32}$. On the one hand, there is ample evidence that the pig model is sensitive to the detection of nanomedicine-induced $\mathrm{CARPA}^{32,33}$. On the other hand, PIMs are not present in the lungs of humans and animals commonly used in preclinical research (mice, rats, dogs and non-human primates) ${ }^{34-36}$. In these animal species, the liver- and spleen-resident macrophages are primarily responsible for nanoparticle clearance. PIMs are induced in humans under certain pathological conditions, such as liver failure ${ }^{34,35}$. In contrast, PIMs are common in the lungs of pigs, sheep and horses, not broadly recognized as preclinical models $\mathrm{s}^{34,35}$. Therefore, one area that requires close attention is the understanding of whether liver- and spleen-resident macrophages in humans play the same role as PIMs in pigs during IRs to nanomedicines. The hypothesis that hepatopulmonary macrophage migration triggers cardiorespiratory symptoms in humans exposed to nanomedicines ${ }^{37}$ is attractive but requires verification. The pivotal role of PIMs in nanoparticle-mediated IRs in the porcine model will benefit from confirmation by various research groups and with various types of nanomaterials. For example, a recent study demonstrated that during the infusion reaction triggered in pigs by carboxylated, hydrophobic, highly anionic polystyrene nanoparticles, complement activation-related opsonization coincided with the peak of pulmonary distress ${ }^{38}$. The relative contribution of the complement and PIMs, as well as the cause-effect relationship, may vary between different types of nanoparticles. Therefore, studies with clinically relevant well-characterized nanomedicines (for example liposomes, micelles, iron-oxides) are essential, while research-grade nanomaterials with poorly understood physicochemical properties (such as polystyrene beads) may not provide clinically relevant answers unless these particles are thoroughly characterized. The nature of a condition (cancer versus inflammatory disorder, for example) treated with a nanodrug should also be considered when analysing the mechanism of IRs to the nanomedicine. Other recently proposed mechanisms, such as those involving platelets as an 
a

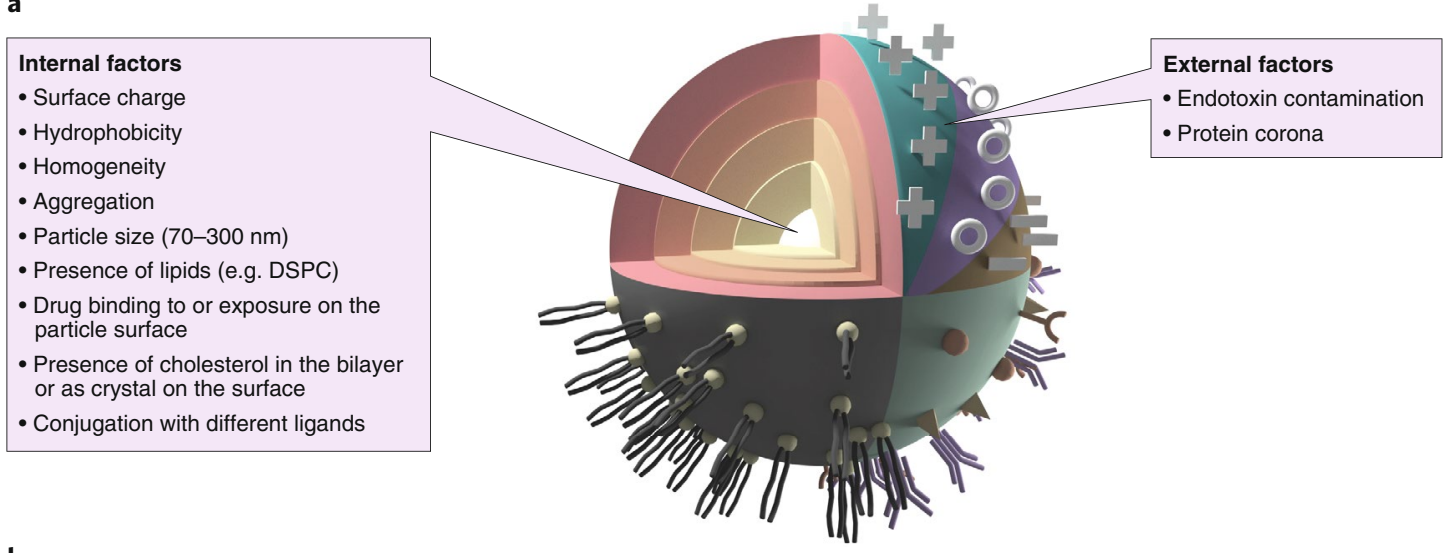

b

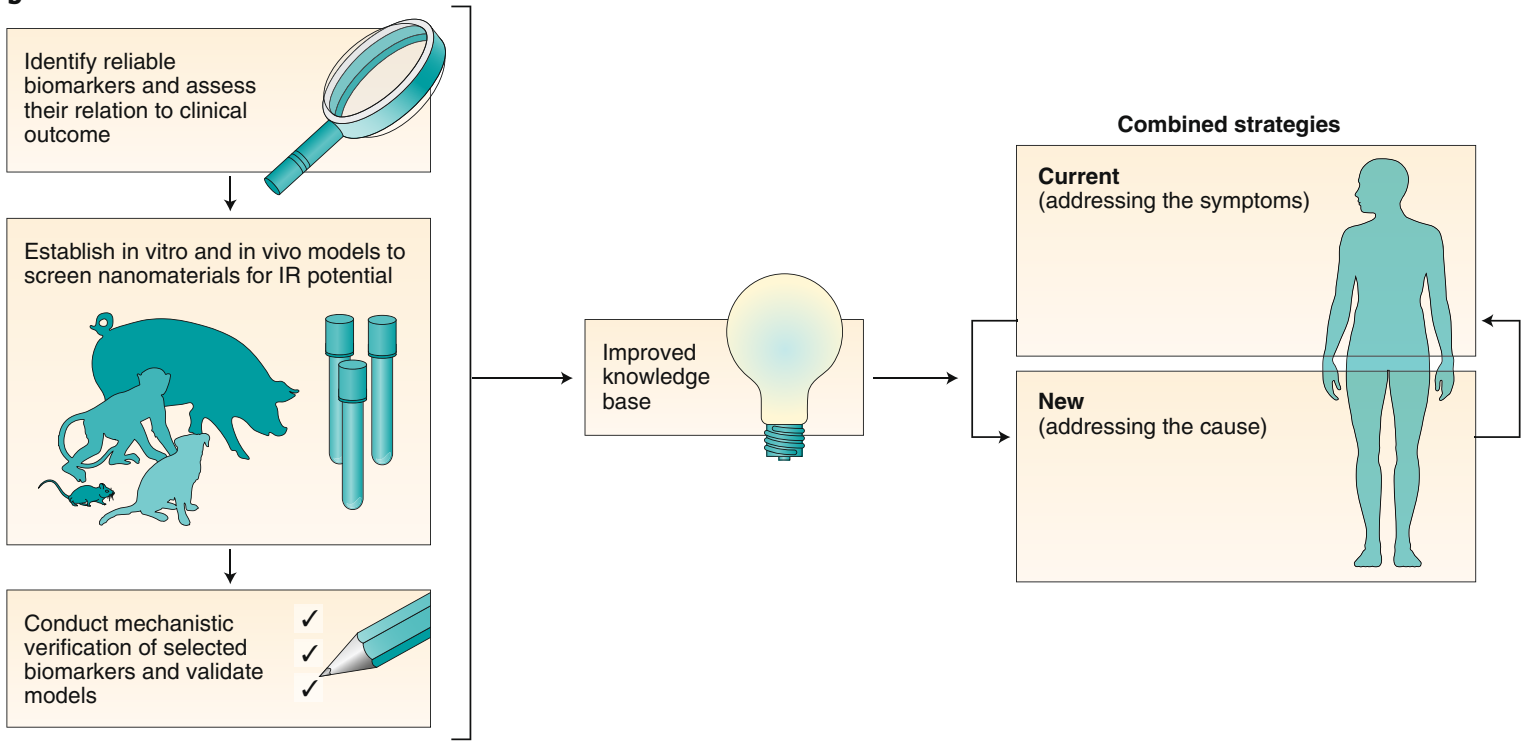

Fig. 1 | Strategy and roadmap for overcoming infusion reactions to nanomedicines. The strategy for overcoming nanomedicine-triggered IRs relies on a mechanistic understanding of those IRs, the identification of the leading cause and the discovery of the relationship between various mechanisms. a, Some physicochemical attributes of nanomedicines that have been linked to IRs. This list is incomplete, as other potential attributes are not yet understood. The known internal properties can be fine-tuned to decrease the risk. External features cannot be controlled directly but can be addressed through the engineering of internal properties. DSPC, 1,2-distearoyl-sn-glycero-3-phosphocholine. b, Identification of reliable biomarkers, corroboration of a methodological framework and mechanistic verification serve to improve the current knowledge base of IRs to nanomedicines. This knowledge will enable improved healthcare by combining existing approaches for monitoring and managing the IRs with new ones, which are aimed at intervention at the root cause.

effector $\operatorname{arm}^{39,40}$, should also be fully investigated in the context of nanoparticle physicochemical properties and interaction with other mechanisms.

Although complement activation in CARPA is commonly verified by assessing the complement split products, there is no universal agreement regarding which macrophage activation markers are relevant to the IRs. Models relevant to the prediction of IR in humans are also being debated ${ }^{31-33,41,42}$. Therefore, there is currently a critical need to verify the biomarkers and models that are necessary for identifying the potential of nanomedicines to cause IRs in patients.

\section{Biomarkers and models of IRs}

The current selection of biomarkers is not straightforward, owing to the controversy over both the definition of IRs ${ }^{43}$ and the mechanism(s) responsible for them ${ }^{31,32}$. A recent approach proposed for therapeutic antibody-mediated IRs based on the long usage of these products in the clinic could serve as a starting point for nanomedicines ${ }^{44}$. In this approach, clinical symptoms of IRs $^{12}$, also called Sampson criteria ${ }^{44}$, are reviewed first to diagnose anaphylaxis $^{44}$. Next, the assessment of drug-specific IgEs (a skin test and enzyme-linked immunosorbent assay, ELISA) and markers of mast cell degranulation (histamine and tryptase) are used to verify the anaphylactic nature of the reaction. Additionally, cytokines (for example interleukin 6 (IL-6), IL-8, interferon $\gamma$, tumour necrosis factor $\alpha$, IL-2 and IL-10), complement split products (C3a, C5a, sC5b-9), and complement consumption (for example CH50) are used to verify IgE-independent pathogenesis of IRs ${ }^{44}$. Re-challenge or avoidance of the allergen is finally used to confirm the $\mathrm{IR}^{44}$. Because anaphylactoid reactions to proteins may also increase the levels of tryptase and cytokines, these biomarkers are debated as suboptimal for diagnosing anaphylaxis to protein-based therapeutics ${ }^{18}$.

In the field of nanomedicine, assessing the complement split products (C3a, C5a, sC5b-9) and consumption ( $\mathrm{CH}-50)$ is used to establish CARPA in both humans and animal models. However, earlier studies with nanomedicines indicated that CARPA response towards liposomes is accompanied by the release of many secondary messengers (for example thromboxane, leukotrienes, eicosanoids, histamines, cytokines and tryptase $)^{18}$. In pigs, thromboxane A2 is 
Table 4 | Available animal models

\begin{tabular}{|c|c|c|c|}
\hline Animal species & Sensitivity to HSR & Advantages & Disadvantages \\
\hline Mouse & Low & Simple and relatively cheap & $\begin{array}{l}\text { Insensitive; not generally accepted for } \\
\text { preclinical safety studies }\end{array}$ \\
\hline Rat & Low & $\begin{array}{l}\text { Simple and relatively cheap; generally } \\
\text { accepted for preclinical safety studies }\end{array}$ & Insensitive \\
\hline Rabbit & Medium-to-high & $\begin{array}{l}\text { Simple and relatively cheap; generally } \\
\text { accepted for pyrogen screening }\end{array}$ & $\begin{array}{l}\text { Unknown relevance to IRs in human patients } \\
\text { except for cytokine release in response to } \\
\text { pyrogens }\end{array}$ \\
\hline Pig & High & $\begin{array}{l}\text { Reproduces clinical symptoms of human } \\
\text { patients; consistent response between } \\
\text { individual animals }\end{array}$ & $\begin{array}{l}\text { Skills- and labour-intensive; not generally } \\
\text { accepted for preclinical safety studies }\end{array}$ \\
\hline Minipig & High & $\begin{array}{l}\text { Reproduces clinical symptoms of human } \\
\text { patients; consistent response between } \\
\text { individual animals }\end{array}$ & $\begin{array}{l}\text { Skills- and labour-intensive; not generally } \\
\text { accepted for preclinical safety studies }\end{array}$ \\
\hline Dog & High & $\begin{array}{l}\text { Reproduces clinical symptoms of human } \\
\text { patients; generally accepted for preclinical } \\
\text { safety studies }\end{array}$ & $\begin{array}{l}\text { High interanimal variability; expensive; ethical } \\
\text { and logistic hurdles }\end{array}$ \\
\hline Non-human primate & Medium-to-high & $\begin{array}{l}\text { Reproduces clinical symptoms of human } \\
\text { patients; generally accepted for preclinical } \\
\text { safety studies }\end{array}$ & Expensive, ethical and logistic hurdles \\
\hline
\end{tabular}

Comparison of haemodynamic and other manifestations of HSRs in animal models. The summary is based on ref. ${ }^{61}$

recognized as the main mediator of pulmonary symptoms commonly seen during IRs. However, the use of this and other secondary messengers for predicting IRs to nanomedicines in humans remains unknown. Although IgG and IgM have been implicated in type II and type III HSRs to proteins and low-molecular-weight drugs $^{41}$, no data exist about such responses to nanomedicines. However, several studies described naturally existing IgM and IgG that can bind to various components commonly present in nanomedicines (cholesterol, phospholipids and PEG) ${ }^{45,46}$. The accelerated blood clearance of PEGylated liposomes due to the anti-PEG $\operatorname{IgM}$ was reported in animals ${ }^{47}$. However, the functional significance and relevance of these and other pre-existing antibodies to nanomedicine-triggered IRs in patients as well as their diagnostic utility require thorough investigation.

Currently, identifying biomarkers that are relevant to IRs depends heavily on in vitro and in vivo models, both of which have advantages and limitations in their relevance to human patients (Table 4). As there is limited information on nanomaterial-mediated type I-IV HSRs, our discussion will focus on models applicable to the two established mechanisms (cytokines and CARPA) and the alternative mechanism (PIMs).

Rodent models reproduce the hypotension observed in humans during IRs. However, the doses required to induce HSRs in mice and rats are several orders of magnitude higher than those needed to trigger reactions in humans ${ }^{42,48}$. Therefore, rodent models are suitable for mechanistic studies but irrelevant for screening materials for reactogenicity.

The dog model reproduces some symptoms of human HSRs, such as hypotension, fainting and other disturbances of vegetative functions, at dose levels relevant to those in humans. However, studies of reactogenicity in dogs require large numbers of animals because of the high inter-animal variability in the response ${ }^{42}$. Therefore, screening for reactogenicity in the dog model may underestimate the toxicity, particularly if the number of tested animals is low.

The pig model allows reproduction of the cardiopulmonary distress typically observed in humans reacting to the infusion of nanomedicines ${ }^{15}$. However, it requires a better characterization and understanding of the role of PIMs ${ }^{34,35}$. Despite differences in the mechanism(s) underlying IRs, the pig model can be used to predict the reactogenicity of nanoparticles at low, clinically relevant doses using a reasonably low number of animals. Other animal models are not well-established to study nanomedicine-induced HSRs.

In vitro studies using patient serum or plasma are often considered for prediction of CARPA to nanomedicines. Likewise, cultures of human peripheral blood mononuclear cells can be used to estimate the risk of CRS induction. The correlation between in vitro screening and in vivo studies has been confirmed for CARPA ${ }^{49}$ and $\mathrm{CRS}^{25}$. However, current experience with these tests suggests that the positive response in complement or cytokine assays can predict the risk, but neither the incidence nor the magnitude, of IRs. This observation is consistent with the multicausality of IRs even when it is evident that complement activation or cytokines are primarily responsible. The utility of basophil activation, mast cell degranulation, leukocyte oxidative burst ${ }^{50}$ and other common laboratory allergy tests ${ }^{51}$ for nanomedicines requires careful investigation.

\section{Strategy and roadmap for addressing IRs to nanomedicines} Translational hurdles due to drug-mediated IRs are not unique to nanotechnology-formulated drug products. Therefore, one way to address the problem in nanomedicine is to use the knowledge and lessons learned from the clinical use of other drug products. For this to happen, the issue must be approached in a systematic way, beginning with the identification of relevant biomarkers in patients, establishing appropriate models and understanding the mechanisms of IRs.

In the first step, reliable biomarkers need to be identified and assessed for correlation to clinical outcomes (Fig. 1b). One approach is to use retrospective clinical trials to identify patients who are sensitive to IRs when administered with nanomedicines. Their sera could be retrieved and tested in vitro. Obtaining viable cells from archived specimens of such patients could be problematic, however, because common preservation techniques protect plasma proteins better than cells. The timeline between specimen collection and nanomedicine administration may also affect the assay outcome because blood composition is dynamic and reflects the physiological status of the patient at the time of collection.

An alternative is through prospective studies that enrol patients prescribed with nanomedicines and collect their fresh blood before and after administration of a nano-drug. Wholeblood samples collected before treatment could be exposed to a 
nanomedicine in vitro, and the various endpoints, including immune cell, complement and clotting cascade activation markers, could be studied. Prospective studies are potentially limited by patients' premedication with immunosuppressive drugs, which are classically used to prevent the incidence of IRs, or by a slow infusion rate, typically used to avoid anaphylaxis. Despite these limitations, some markers (such as complement split products or cytokines) can still be detected, even in the absence of clinical signs of HSRs. For example, in the case of Doxil and Taxol infused at high rates, HSR symptoms were detected in patients only when high levels (more than fivefold above the baseline) of the terminal complex (sC5b-9) were detected in the blood ${ }^{52,53}$. However, complement split products at physiologically significant levels (at least twofold above the baseline) were detectable in the absence of clinical symptoms of HSRs ${ }^{19}$.

The second step requires the establishment of in vivo and in vitro models and their relevance to human patients. One way is to take advantage of existing models. To verify their relevance to humans, one must compare the underlying mechanism(s) between these models and patients. Although several mechanisms of IRs have been proposed for nanomedicines, CARPA is the most wellstudied and understood ${ }^{32}$. The relevance of other mechanisms to nanomedicines remains unclear, given the current lack of human data. This work, therefore, is critical and interdependent on biomarker selection.

The third step is mechanistic verification of the selected biomarkers. Here we propose the use of inhibitors in patients when approved drugs are available. For example, a clinically approved C5 inhibitory antibody, eculizumab (Soliris); a plasma-derived $\mathrm{C} 1$ inhibitor (C1INH); and a small-molecule inhibitor of factor D could be used to understand the contribution of the complement in humans ${ }^{54}$. Because it is not yet known what inhibitor would work best for preventing nanoparticle-induced complement activation in patients, non-clinical-grade inhibitors of C3 convertase (compstatin, APT070 or APL-2), soluble complement receptors (sCD35) and decay accelerating factor (CD55), chimeric receptors (CAB-2) or their animal counterparts could be investigated in the animal models. For example, sCD35 was effective at inhibiting liposometriggered IRs in the pig model of CARPA ${ }^{55}$.

The contribution of other mechanisms (CRS, platelets, and direct macrophage activation, for example) could be verified by inhibitors of cyclooxygenase (such as indomethacin) and cytokines (such as neutralizing antibodies). For example, indomethacin efficiently blocked liposome-mediated IRs in pigs, suggesting cooperation between macrophage- and complement-mediated mechanisms ${ }^{55}$. Special consideration should be given to the type of the nanomedicine tested (for example PEGylated liposome or dextran-coated iron oxides), and the category of human subjects enrolled in the clinical trial. For example, the consequences of administering a complement inhibitor to cancer patients prescribed with Doxil are uncertain because the implications of complement in tumour growth are poorly understood. Likewise, inhibiting complement in patients with chronic kidney disease who had been prescribed Feraheme may increase the risk of infections because the immune system in these patients is already weakened, and complement-mediated protection from pathogens is further reduced by the inhibitor. The administration of empty carriers in combination with complement inhibitors can be much less dangerous and more ethically justified in healthy volunteers.

Desensitization strategy, commonly used in the field of protein-based allergens, is not well investigated in the field of nanomedicine. The only known preclinical example involves injecting Doxebo (a placebo PEGylated liposome) to reduce the IRs to subsequently administered Doxil (a drug-loaded PEGylated liposome) in a pig model ${ }^{29}$. Clinical investigation of this and other desensitization strategies would further benefit the field.
The current approach of slowing down the infusion rate is a powerful tool in reducing IRs to nanomedicines ${ }^{19}$, and it would further benefit from an understanding of the underlying mechanism. The improved knowledge base will also allow researchers to unravel the complex relationship between IRs, other immune-mediated adverse effects, and long-term or tissue-specific toxicities similar to those described in rats with CARPA induced by a high dose of cholesterol-rich liposomes ${ }^{56}$.

\section{Conclusion}

The foundation of the strategy to overcome IRs to nanomedicines comprises a mechanistic understanding of those IRs and the identification of the leading cause and relationship between various mechanisms, as well as critical attributes of the nanomedicines that are responsible for triggering IRs. The nanomedicine community must clarify the role of the complement, cytokines, macrophages, platelets and other mechanisms in the context of the physicochemical attributes of the nanoparticles. In the long run, this information can be used to understand the potential role of IRs in tissue-specific and long-term toxicities. Furthermore, the community needs to harmonize methods, models and biomarkers for predicting IRs in patients. Finally, the improved knowledge should be used to combine existing strategies (which focus on management of the symptoms) with new ones (which focus on intervening at the root of the cause) to overcome translational barriers caused by IRs.

Received: 16 April 2018; Accepted: 3 September 2018; Published online: 22 October 2018

\section{References}

1. Joerger, M. Prevention and handling of acute allergic and infusion reactions in oncology. Ann. Oncol. 23(Suppl. 10), x313-x319 (2012).

2. Johansson, S. G. et al. A revised nomenclature for allergy. An EAACI position statement from the EAACI nomenclature task force. Allergy 56, 813-824 (2001)

3. Jutel, M. et al. International consensus on allergy immunotherapy. J. Allergy Clin. Immunol. 136, 556-568 (2015).

4. Lenz, H. J. Management and preparedness for infusion and hypersensitivity reactions. Oncologist 12, 601-609 (2007)

5. Simons, F. E. et al. 2015 update of the evidence base: World Allergy Organization anaphylaxis guidelines. World Allergy Organ J. 8, 32 (2015).

6. Rosello, S., Blasco, I., Garcia Fabregat, L., Cervantes, A. \& Jordan, K. Management of infusion reactions to systemic anticancer therapy: ESMO Clinical Practice Guidelines. Ann. Oncol. 28(Suppl. 4), iv100-iv118 (2017). Describes clinical approaches for addressing infusion reactions commonly experienced in response to oncology drugs.

7. Torres, M. J. et al. Approach to the diagnosis of drug hypersensitivity reactions: similarities and differences between Europe and North America. Clin. Transl. Allergy 7, 7 (2017).

8. The National Cancer Institute Common Terminology Criteria for Adverse Events (NCI CTCAE v.5) (US DDepatartment of Health and Human Services, 2017).

9. Gell, P. G. H. \& Coombs, R. R. A. in Clinical Aspects of Immunology (eds Gell, P. G. H. \& Coombs, R. R. A.) 575-596 (Blackwell, Oxford, 1963). Provides classification of allergic reactions based on the underlying mechanisms. It is still among the most commonly used classifications of allergy.

10. Khan, D. A. Hypersensitivity and immunologic reactions to biologics: opportunities for the allergist. Ann. Allergy Asthma Immunol. 117, 115-120 (2016).

11. Patel, S. V. \& Khan, D. A. Adverse reactions to biologic therapy. Immunol. Allergy Clin. North Am. 37, 397-412 (2017).

12. Sampson, H. A. et al. Second symposium on the definition and management of anaphylaxis: Summary Report. Second National Institute of Allergy and Infectious Disease/Food Allergy and Anaphylaxis Network symposium. J. Allergy Clin. Immunol. 117, 391-397 (2006).

13. Lorenzo-Abalde, S. \& Gonzalez-Fernandez, A. in Handbook of Immunological Properties of Engineered Nanomaterials (eds Dobrovolskaia, M. A. \& McNeil, S. E.) 517-546 (World Scientific, Singapore, 2013).

14. Szebeni, J. et al. A porcine model of complement-mediated infusion reactions to drug carrier nanosystems and other medicines. Adv. Drug Deliv. Rev. 64, 1706-1716 (2012).

15. Szebeni, J., Bedőcs, P., Dézsi, L. \& Urbanics, R. A porcine model of complement activation-related pseudoallergy to nanopharmaceuticals: pros 
and cons of translation to a preclinical safety test. Precision Nanomed. 1, 63-75 (2018).

Most recent review of the porcine CARPA model, highlighting the model's pros and cons and the fact that it is a disease model (that of hypersensitivity), rather than a model of normal human response to IV-administered nanoparticles.

16. Markman, M. et al. Paclitaxel-associated hypersensitivity reactions: experience of the gynecologic oncology program of the Cleveland Clinic Cancer Center. J. Clin. Oncol. 18, 102-105 (2000).

17. Postmarketing Safety Review (FDA, 2005); https://www.fdagov/ohrms/dockets/ ac/05/briefing/2005-4095B1_02_15-FDA-Tab-7-10pdf

18. Szebeni, J. Complement activation-related pseudoallergy: a stress reaction in blood triggered by nanomedicines and biologicals. Mol. Immunol. 61, 163-173 (2014).

A comprehensive summary of the CARPA theory proposing that the phenomenon represents a stress reaction in blood, an universal acute defense mechanism against foreign microbes along the immunocirculatory axis.

19. Szebeni, J., Muggia, F., Gabizon, A. \& Barenholz, Y. Activation of complement by therapeutic liposomes and other lipid excipient-based therapeutic products: prediction and prevention. Adv. Drug Deliv. Rev. 63, 1020-1030 (2011).

20. Canna, S. W. \& Behrens, E. M. Making sense of the cytokine storm: a conceptual framework for understanding, diagnosing, and treating hemophagocytic syndromes. Pediatr. Clin. North Am. 59, 329-344 (2012).

21. DeFrancesco, L. CAR-T cell therapy seeks strategies to harness cytokine storm. Nat. Biotechnol. 32, 604 (2014).

22. Tyrsin, D. et al. From TGN1412 to TAB08: the return of CD28 superagonist therapy to clinical development for the treatment of rheumatoid arthritis. Clin. Exp. Rheumatol. 34(Suppl. 98), 45-48 (2016).

23. Rupaimoole, R. \& Slack, F. J. MicroRNA therapeutics: towards a new era for the management of cancer and other diseases. Nat. Rev. Drug Discov. 16, 203-222 (2017).

24. Chousterman, B. G., Swirski, F. K. \& Weber, G. F. Cytokine storm and sepsis disease pathogenesis. Semin. Immunopathol. 39, 517-528 (2017)

25. Dobrovolskaia, M. A. Pre-clinical immunotoxicity studies of nanotechnologyformulated drugs: challenges, considerations and strategy. J. Control. Release 220, 571-583 (2015)

26. D'Mello, S. R. et al. The evolving landscape of drug products containing nanomaterials in the United States. Nat. Nanotech. 12, 523-529 (2017).

27. Granot, Y. \& Peer, D. Delivering the right message: challenges and opportunities in lipid nanoparticles-mediated modified mRNA therapeutics an innate immune system standpoint. Semin. Immunol. 34, 68-77 (2017). Provides a comprehensive summary of the current literature regarding immunological recognition of and inflammation in response to lipid nanocarriers commonly used in drug delivery.

28. Landesman-Milo, D. \& Peer, D. Altering the immune response with lipid-based nanoparticles. J. Control. Release 161, 600-608 (2012).

29. Szebeni, J. et al. Prevention of infusion reactions to PEGylated liposomal doxorubicin via tachyphylaxis induction by placebo vesicles: a porcine model. J. Control. Release 160, 382-387 (2012).

30. Wibroe, P. P. et al. Bypassing adverse injection reactions to nanoparticles through shape modification and attachment to erythrocytes. Nat. Nanotech. 12, 589-594 (2017).

The pulmonary hypertensive effect of polystyrene nanoparticles is shown to depend on particle shape, macrophage phagocytosis and erythrocyte binding, but not on the complement activation. The study initiated hot debates regarding the mechanism underlying infusion reactions.

31. Moghimi, S. M. Nanomedicine safety in preclinical and clinical development: focus on idiosyncratic injection/infusion reactions. Drug Discov. Today $\mathbf{2 3}$ 1034-1042 (2017)

A position paper proposing that IRs are due to the robust nanoparticle clearance from the blood by macrophages, regardless of complement activation ('rapid phagocytic response' hypothesis). The concept is debated in refs 32 and 38.

32. Szebeni, J. Mechanism of nanoparticle-induced hypersensitivity in pigs: complement or not complement? Drug Discov. Today 23, 487-492 (2018). Review of the evidence for complement activation to play a causal role in infusion reactions and the pitfalls of complement assays. This position paper challenges the rapid phagocytic response hypothesis proposed by refs 30 and 31 .

33. Jackman, J. A. et al. Comparison of complement activation-related pseudoallergy in miniature and domestic pigs: foundation of a validatable immune toxicity model. Nanomedicine 12, 933-943 (2016).

34. Schneberger, D., Aharonson-Raz, K. \& Singh, B. Pulmonary intravascular macrophages and lung health: what are we missing? Am. J. Physiol. Lung Cell. Mol. Physiol. 302, L498-L503 (2012).
35. Winkler, G. C. Pulmonary intravascular macrophages in domestic animal species: review of structural and functional properties. Am. J. Anat. 181, 217-234 (1988).

36. Brain, J. D., Molina, R. M., DeCamp, M. M. \& Warner, A. E. Pulmonary intravascular macrophages: their contribution to the mononuclear phagocyte system in 13 species. Am. J. Physiol. 276, L146-L154 (1999). (1 Pt 1).

37. Csukás, D., Urbanics, R., Wéber, G., Rosivall, L. \& Szebeni, J. Pulmonary intravascular macrophages: prime suspects as cellular mediators of porcine CARPA. Eur. J. Nanomed. 7, 27-36 (2015).

38. Mészáros, T. et al. Involvement of complement activation in the pulmonary vasoactivity of polystyrene nanoparticles in pigs: unique surface properties underlying alternative pathway activation and instant opsonization. Int. J. Nanomed. (in the press).

Evidence that complement activation plays a role in the pulmonary reactivity of polystyrene nanospheres in pigs. The study highlights the relevance of the porcine CARPA model in preclinical safety testing of nanomedicines.

39. Beutier, H. et al. Platelets expressing IgG receptor FcgammaRIIA/CD32A determine the severity of experimental anaphylaxis. Sci. Immunol. 3, eaan5997 (2018)

This study demonstrates the contribution of platelets to drug-mediated anaphylaxis in a mouse model engineered to express human receptor for immunoglobulin G, Fc $\gamma$ IIA (CD32A)

40. Patko, Z. \& Szebeni, J. Blood cell changes in complement activation-related pseudoallergy. Eur. J. Nanomed. 7, 233-244 (2015).

41. Song, S., Yang, L., Trepicchio, W. L. \& Wyant, T. Understanding the supersensitive anti-drug antibody assay: unexpected high anti-drug antibody incidence and its clinical relevance. J. Immunol. Res. 2016, 3072586 (2016).

42. Szebeni, J. et al. Animal models of complement-mediated hypersensitivity reactions to liposomes and other lipid-based nanoparticles. J. Liposome Res. 17, 107-117 (2007).

43. Johansson, S. G. et al. Revised nomenclature for allergy for global use: report of the Nomenclature Review Committee of the World Allergy Organization, October 2003. J. Allergy Clin. Immunol. 113, 832-836 (2004).

44. Doessegger, L. \& Banholzer, M. L. Clinical development methodology for infusion-related reactions with monoclonal antibodies. Clin. Transl. Immunol. 4, 1-9 (2015).

45. Szebeni, J., Wassef, N. M., Rudolph, A. S. \& Alving, C. R. Complement activation in human serum by liposome-encapsulated hemoglobin: the role of natural anti-phospholipid antibodies. Biochim. Biophys. Acta 1285 127-130 (1996).

46. Chen, B. M. et al. Measurement of pre-existing IgG and IgM antibodies against polyethylene glycol in healthy individuals. Anal. Chem. 88, 10661-10666 (2016).

47. Hashimoto, Y., Shimizu, T., Abu Lila, A. S., Ishida, T. \& Kiwada, H. Relationship between the concentration of anti-polyethylene glycol (PEG) immunoglobulin $\mathrm{M}(\mathrm{IgM})$ and the intensity of the accelerated blood clearance $(\mathrm{ABC})$ phenomenon against PEGylated liposomes in mice. Biol. Pharm. Bull. 38, 417-424 (2015).

48. Dezsi, L. et al. Features of complement activation-related pseudoallergy to liposomes with different surface charge and PEGylation: comparison of the porcine and rat responses. J. Control. Release 195, 2-10 (2014).

49. Kozma, G. T. et al. Variable association of complement activation by rituximab and paclitaxel in cancer patients in vivo and in their screening serum in vitro with clinical manifestations of hypersensitivity: a pilot study. Eur. J. Nanomed. 7, 289-301 (2015).

50. Lozano-Fernandez, T. et al. Potential impact of metal oxide nanoparticles on the immune system: the role of integrins, L-selectin and the chemokine receptor CXCR4. Nanomedicine 10, 1301-1310 (2014).

51. Savi, E., Peveri, S., Cavaliere, C., Masieri, S. \& Montagni, M. Laboratory tests for allergy diagnosis. J. Biol. Regul. Homeost. Agents 32(1 Suppl. 1), 25-28 (2018).

52. Chanan-Khan, A. et al. Complement activation following first exposure to pegylated liposomal doxorubicin (Doxil): possible role in hypersensitivity reactions. Ann. Oncol. 14, 1430-1437 (2003).

53. Kozma Gergely, T. et al. Variable association of complement activation by rituximab and paclitaxel in cancer patients in vivo and in their screening serum in vitro with clinical manifestations of hypersensitivity: a pilot study Eur. J. Nanomed. 7, 289-301 (2015).

54. Morgan, B. P. \& Harris, C. L. Complement, a target for therapy in inflammatory and degenerative diseases. Nat. Rev. Drug Discov. 14 857-877 (2015)

55. Szebeni, J. et al. Hemodynamic changes induced by liposomes and liposome-encapsulated hemoglobin in pigs: a model for pseudoallergic cardiopulmonary reactions to liposomes. Role of complement and inhibition by soluble CR1 and anti-C5a antibody. Circulation 99, 2302-2309 (1999).

56. Baranyi, L. et al. Complement-dependent shock and tissue damage induced by intravenous injection of cholesterol-enriched liposomes in rats. J. Appl. Res. 3, 221-231 (2003) 
57. Picard, M. \& Galvao, V. R. Current knowledge and management of hypersensitivity reactions to monoclonal antibodies. J. Allergy Clin. Immunol. Pract. 5, 600-609 (2017).

58. VYXEOS: warning and precautions (accessed 18 August 2018); https://vyxeospro.com/?gclid= EAIaIQobChMIvJurn4jt3AIVx1mGCh3pSwXhEAAYASAAEgK1RvD BwE.

59. Onyvide: important safety information (accessed 18 August 2018); https://www.onivyde.com/important-safety-information

60. Corominas, M., Gastaminza, G. \& Lobera, T. Hypersensitivity reactions to biological drugs. J. Investig. Allergol. Clin. Immunol. 24, 212-225 (2014).

61. Szebeni, J. Hemocompatibility testing for nanomedicines and biologicals: predictive assays for complement mediated infusion reactions. Eur. J. Nanomed. 5, 33-53 (2012).

\section{Acknowledgements}

The study was supported in part (M.A.D.) by federal funds from the National Cancer Institute, National Institutes of Health (NIH), under contract HHSN261200800001E, and by NIH grants CA194058 (D.S.) and EB022040 (D.S.). The content of this publication does not necessarily reflect the views or policies of the Department of Health and Human Services, nor does mention of trade names, commercial products, or organizations imply endorsement by the US Government. J.S. acknowledges support by the European Union Seventh Framework Program grants NMP-2012-309820 (NanoAthero) and NMP2013-602923 (TheraGlio), and by the Applied Materials and Nanotechnology Center of Excellence at Miskolc University, Hungary. Y.B. acknowledges the partial support of the Barenholz Fund, which was established by the Hebrew University with royalties obtained from Y.B.'s inventions and is used to support research in the Barenholz Lab. The work of A.G.F. was funded by Xunta de Galicia (Grupo de referencia competitiva ED431C 2016041). We thank A. L. Chun of Science Story Lab for comments.

\section{Author contributions}

All authors wrote the paper.

\section{Competing interests}

J.S. is involved in SeroScience Ltd's CRO activity providing immune toxicology services. J.S. and Y.B. are co-inventors on US patent 9,078,812B2, 14 July 2015, relevant to the use of liposomal carrier as desensitizing agent and co-owned by Semmelweis University, Hungary and Hebrew University, Israel. Y.B. is one of the inventors of two patents relevant to Doxil: US Patent 5,192,549, 9 March 1993, and US Patent 5,316,771, 31 May 1994. Both patents expired in March 2010. The Hebrew University received royalties from Doxil sales until the patent expiration. The Barenholz Fund, established with a portion of these royalties, is used to support research in Y.B.'s laboratory, including this study. The other authors declare no competing interests related to the subject described in the manuscript.

\section{Additional information}

Reprints and permissions information is available at www.nature.com/reprints.

Correspondence should be addressed to M.A.D.

Publisher's note: Springer Nature remains neutral with regard to jurisdictional claims in published maps and institutional affiliations.

(C) This is a U.S. government work and not under copyright protection in the U.S.; foreign copyright protection may apply 2018 